\title{
Monuments under threat: environmental impact, preservation strategies and natural stone recourses
}

\author{
Siegfried Siegesmund $\cdot$ Joerg Ruedrich
}

Received: 6 March 2011 / Accepted: 19 March 2011/Published online: 6 April 2011

(c) The Author(s) 2011. This article is published with open access at Springerlink.com

On the Earth's surface, natural building stones are subjected to the influences of the atmosphere, hydrosphere and biosphere. Different weathering processes result when these spheres interact with geomaterials that in the long run lead to the disintegration of natural building stones. In the past 150 years, anthropogenic influences consisting of artificial emissions have lead to the most prevalent changes in the atmosphere. Urban environments contain innumerable buildings and works of art constructed from the natural stone that are exposed to weathering. In these environments, the weathering processes are negatively influenced through the emission of suspended particles and gases.

An important theme of the future is local and global climatic change, whether it will be man-made or of a natural origin. The migration of climatic zones will also change the local conditions of monuments all around the globe, not only the intensification of particular weather conditions that may lead up to natural catastrophes.

Today, special weather events such as storms and torrential rains as well as heat waves will continue to increase. The changing climatic situation will significantly affect the temperature and moisture balance of monuments and facades built from the natural stone. Likewise, the migration of climate zones is already evident today and the further advancement is a cause for alarm. Rising temperatures in regions with permafrost in winter periods will lead to increase in freeze-thaw cycles. However, positive

S. Siegesmund $(\bowtie) \cdot$ J. Ruedrich

GZG, Structural Geology and Geodynamics, University of

Göttingen, Goldschmidtstr. 3, 37077 Göttingen, Germany

e-mail: ssieges@gwdg.de effects for the specific regions cannot be ruled out. Local warming of the climate in some regions can cause the occurrence of freeze-thaw cycles to decrease.

Since buildings and monuments are subjected to longterm weathering processes, the growing number of objects worthy of protection is increasing, which leads to a huge rise in the costs for preservation and maintenance. Due to this situation, improved preservation strategies are being developed for the protection of humanity's cultural heritage. In the past several years, different focal points have emerged. These include: (1) scientific research on the materials and their properties and how they interact with environmental influences for a better understanding of weathering processes, (2) research on the material compatibility between the natural stone and conservation and consolidation methods, and (3) improved protection of monuments through regular maintenance based on the optimised structural measures of inventory and the development of priority lists.

The Earth's surface shows an enormous volume and a great diversity of natural stones. Only a few, however, are suitable for being used as a natural building stone. Since nature does not create the corresponding rocks in the lifespan of a human being, the exploitation of these rocks and the availability of good natural stones will most likely continue to decrease. One example is the Carrara Marble (Italy), which has been excavated from a large number of quarries over the past 2000 years. It is becoming increasingly clear in the present societal discussion concerning the resource conservation for future generations, that today's society needs to develop a sustainable way in the utilisation of natural resources. Consequently, the future excavation of natural stones will result in conditions that are essentially driven by resource conserving exploitation, whereby the volume of cuttings and waste will be reduced. In 
addition, the assurance of quality, which is based on a better understanding of local weathering processes, is an important problem for present and future natural resource exploitation.
Open Access This article is distributed under the terms of the Creative Commons Attribution Noncommercial License which permits any noncommercial use, distribution, and reproduction in any medium, provided the original author(s) and source are credited. 